\title{
STRIP KOMIK SEBAGAI WADAH PERISTIWA BUDAYA
}

\author{
Ayu Ida Savitri \\ Jurusan Sastra Inggris, Fakultas Ilmu Budaya \\ Universitas Diponegoro, \\ aidaarsjaad@gmail.com
}

\begin{abstract}
Comic Strip is "a short series of amusing drawings with a small amount of writing which is usually published in a newspaper" (Cambridge 2003: 239). It usually contains stories of what happened at the moment of the comic strips published in the newspaper. That is why, although it cannot be considered as a historical document, it can be considered as a medium of factual events happening at the moment of the newspaper published, delivered in an entertaining packaging. One of those factual events is cultural event related to the culture of the people where the newspaper published. Those events can be considered as cultural one by revealing the readers' interpretation of the comic strips by using semiotic and pragmatic theories to see whether the events is considered as part of their culture or not. As comic strip consists of pictures and utterances, the analysis can be done by using Semiotics theory to analyse its picture (visual element) and Pragmatics theory to analyse its utterance (verbal element). Firstly, the informant reveals the conversational implicature of the utterances. The result is then analysed by using the Relevance Theory from Sperber and Wilson (1986: 1996) to describe the utterances' meaning, how they get it, and why they get it that way. Secondly, the informant interprets the comic strip (the picture along with the utterance's analysis). The result is then analysed by using the Signifying Order Theory by Danesi and Perron (1999) to describe the comic strip's meaning, how they get it, and why they get it that way.
\end{abstract}

Keywords: comic strip, coversational implicature, relevance theory, interpretation, signifying order

\section{Pendahuluan}

Strip komik adalah sederet panil (panel) berisi gambar-gambar yang disertai dengan tulisan, yang menceritakan kisah yang menghibur. Strip komik yang dibukukan dan diterbitkan secara mandiri (tidak menjadi bagian dari terbitan lain seperti surat kabar atau majalah) disebut buku komik (comic book) atau yang lebih dikenal dengan komik (comic) saja. Buku komik dapat dibuat dan diterbitkan tidak berdasarkan strip komiknya (bukan strip komik yang dibukukan) (Sabin, 1996: 1525).

Penelusuran sejarah strip komik oleh Kunzle (1973) menemukan adanya broadsheet yang ditemukan pada kurun waktu 1450 hingga 1825, yaitu teks yang mengangkat topik sosial atau politik, yang dicetak di atas selembar kertas, yang dapat disertai atau tidak disertai dengan ilustrasi (Kunzle, 1973: 4). Broadsheet berisi propaganda agama, kekerasan politik, atau kritik sosial yang terjadi dalam masyarakat di pelbagai wilayah Eropa pada masa itu.

Kunzle kemudian (1973: 6) menyebut broadsheet sebagai cerita bergambar (picture story) yang menjadi awal mula strip komik (early strip comic). Broadsheet juga ia pandang sebagai awal mula kartun (cartoon) yang dimuat di media cetak, yaitu sebuah panil 
(single panel) berisi lelucon dalam bentuk grafis (graphic joke) atau ilustrasi yang bersifat jenaka (humorous illustration) (Kunzle, 1973: 2).

Kartun berisi lelucon bersifat satir disebut karikatur (caricature), sedangkan kartun dalam bentuk deretan panil disebut kartun komik (comic cartoon), yang menurut Wijana (2003: 11) berisi "komentar humoristis tentang suatu peristiwa atau masalah aktual". Dalam hal ini, strip komik merupakan bagian dari kartun komik yang berupa rangkaian panil yang mengangkat hal yang sedang terjadi pada saat strip komik dimuat dengan cara yang menghibur.

Karena strip komik pada umumnya dimuat secara berkala di dalam sebuah terbitan (surat kabar, majalah, buletin, dll.) dan mengangkat topik yang sedang hangat dibicarakan pada saat terbitan itu muncul, maka dapat dikatakan bahwa topik yang diangkat bersifat aktual karena berkaitan dengan pelbagai peristiwa yang sedang berlangsung di uatu masyarakat pada saat strip komik tersebut dimuat.

Strip komik awal di Eropa merefleksikan kondisi sosial, politik dan moral di pelbagai wilayah di Eropa pada abad XV-XIX (Kunzle, 1973: 4). Sementara itu, komik tradisional di Indonesia mencerminkan kondisi sosial, politik dan moral pada masa kerajaan Hindu dan Budha seperti yang terdapat di dalam wayang beber, relief cerita candi, dan cerita lontar (Tabrani, 2005: 69-76).

Meskipun tidak dapat dianggap sebagai dokumen sejarah, strip komik dapat digunakan untuk memperoleh informasi tentang segala sesuatu yang terdapat dalam masyarakat tertentu, pada kurun waktu tertentu pula karena strip komik merupakan wadah peristiwa faktual yang terjadi pada saat dimuat meskipun dikemas dalam bentuk hiburan. Jika strip komik tidak dapat dianggap sebagai fakta sejarah, strip komik dapat dipandang sebagai refleksi budaya masyarakat tempat strip komik tumbuh dan berkembang. Cerminan budaya tersebut dapat diperoleh dari hasil pembacaan strip komik oleh pembacanya. Dalam hal ini, pembacaan berarti pemaknaan atas peristiwa budaya yang terdapat di dalam strip komik.

Karena pemaknaan strip komik sebagai sebuah objek - bersifat terbuka, dimana pembaca - sebagai subjek -dapat bebas memaknainya berdasarkan pengetahuan mereka, hasil pemaknaan strip komik menjelaskan mengapa pembaca memaknainya demikan. Hasil tersebut merupakan gambaran dan penjelasan tentang kebudayaan masyarakat tempat strip komik berada dan pandangan pembaca tentang kebudayaan tersebut.

Dalam penelitian ini, makna ujaran dalam strip komik dianalisis menggunakan teori Pragmatik, yaitu Teori Relevansi dari Sperber dan Wilson (1986: 1995) untuk mengungkapkan implikatur percakapan. Sementara itu, makna strip komik secara menyeluruh dianalisis menggunakan teori Semiotik, yaitu Teori Signifying Order dari Danesi dan Perron (1999) untuk mengungkapkan makna strip komik bagi pembacanya dan mengapa pembaca memaknainya demikian.

\section{Pemaknaan Strip Komik Menggunakan Teori Pragmatik}

Thomas (1995: 22) menyatakan bahwa manusia berinteraksi dengan menggunakan bahasa sebagai sarana untuk saling memahami dan mencari makna dalam interaksi (meaning in interaction). Dalam penelitian ini, makna interaksi antar-tokoh dalam strip komik diperoleh dengan memaknai bahasa, yaitu ujaran, yang digunakan di dalam interaksi mereka.

Ujaran tokoh strip komik umumnya mengandung implikatur percakapan untuk memantik tawa (menimbulkan humor) atau menyindir pembaca (bersifat 
satir) dalam ruang (panil) yang terbatas. Dalam hal ini, teori Pragmatik, digunakan untuk mengkaji implikatur percakapan yang lazim digunakan di dalam strip komik untuk menunjang perngungkapan humor yang bersifat satir, yang digunakan sebagai alat kritik untuk menghindari ketersinggungan pihak yang dijadikan objek lelucon

Teori Relevansi Sperber dan Wilson (1986: 1995) merangkum seluruh bidal dalam Prinsip Kerjasama Grice (1867: 1975) menjadi satu bidal saja, yaitu relasi (relation) atau relevansi yang kemudian dinaikkan tingkatnya menjadi Prinsip Relevansi sebagai kaidah berkomunikasi yang menyatakan bahwa pada setiap tindak komunikasi yang ostensif (ostensive communication act) terdapat relevansi optimal (optimum relevance). Jika relevansi tindak komunikasi penutur (speaker) tidak optimal, komunikasi yang dijalankannya tidak ostensif sehingga ia telah melanggar Prinsip Relevansi.

Dalam hal ini, kontribusi penutur dianggap relevan hanya jika ujarannya memiliki efek kontekstual (mengandung informasi baru yang berkaitan dengan informasi lama yang tersimpan di dalam benak petutur (hearer), sehingga ujaran penutur akan diproses (dipahami) dengan mudah oleh petutur. Semakin mudah petutur memahami ujaran penutur (semakin kecil usaha pemrosesan ujaran), semakin tinggi derajad relevansi ujaran penutur.

Oleh karena itu, penutur hendaknya memanifestasikan relevansi optimal dalam ujarannya agar petutur dapat mengidentifikasinya sehingga ia dapat dengan mudah memahami maksud dari ujaran penutur. Petutur hanya akan memroses informasi (dalam ujaran) dengan efek kontekstual terbanyak dan usaha pemrosesan terkecil, yaitu ujaran dengan implikatur percakapan yang kuat sehingga inferensi dalam ujaran tersebut dapat dipeoleh petutur dengan mudah.
Dalam penelitian ini, penutur adalah penulis/pencipta strip komik yang merepresentasikan maksudnya melalui ujaran tokoh strip komik buatannya, sedangkan petutur adalah pembaca

Teori Relevansi Sperber dan Wilson (1986: 1995) dipilih untuk mengetahui bagaimana pembaca memaknai ujaran yang mengandung implikatur percakapan yang terdapat di dalam strip komik. Berdasarkan teori tersebut, relevansi dalam ujaran tokoh strip komik dapat mengungkapkan implikatur percakapan yang digunakan dan tujuan penggunaannya di dalam sebuah situasi komunikasi. Dengan demikian, dapat diketahui bagaimana pembaca memperoleh implikatur percakapan dalam strip komik sehingga dapat diketahui pula bagaimana mereka memperoleh makna ujaran setiap tokoh di dalam strip komik tersebut.

\section{Pemaknaan Strip Komik Menggunakan Teori Semiotik \\ Peirce (1983: 1914) dalam Nöth} (1995: 42) menyatakan bahwa tanda adalah sesuatu yang dianggap sebagai tanda oleh orang yang menginterpretasikannya sebagai tanda. Tanda sendiri terwujud atas relasi antara tanda dan maknanya, yaitu antara sesuatu yang dianggap dan diinterpretasikan sebagai tanda dengan sesuatu yang dirujuknya, dalam relasi yang bersifat konvensional (komunal).

Peirce menginterpretasi tanda dalam Proses Semiosis, yang menghubungkan tanda, sesuatu yang ditandainya, dan interpretai tanda, dalam sebuah relasi yang bersifat triadik sehingga model interpretasi tanda di dalam proses semiosis disebut model relasi triadik. Dalam proses tersebut, tanda dipandang sebagai sebuah representamen atau ground, yaitu sesuatu yang dapat diindera oleh manusia. Dalam kognisi, representamen dihubungkan dengan sesuatu yang ditandainya, yang 
disebut objek. Masih dalam kognisi, objek diinterpretasikan sehingga menghasilkan interpretant (hasil interpretasi objek). Proses semiosis dapat berlangsung secara terus-menerus (ad infinitum), di mana interpretant dapat kembali menjadi representamen yang kemudian dapat kembali diinterpretasikan menjadi interpretant lain.

Dalam hal ini, proses semiosis berhenti pada tahap deskripsi makna tanda bagi interpreter. Untuk memperoleh penjelasan atas pertanyaan mengapa interpreter memaknai tanda demikian diperlukan kajian yang menghubungkan proses dan hasil interpretasi tanda dalam proses semiosis dengan latar belakang sosial dan budaya interpreter. Selanjutnya, analisis semiotik lanjutan dilakukan menggunakan Proses Signifikasi Kultural dari Danesi dan Perron (1999) untuk memperoleh gambaran tentang alasan pembaca mengemukakan interpretasinya.

Danesi dan Perron (1999: 68) mendefinikan semiosis sebagai kemampuan berpikir yang dimiliki oleh seseorang, yang mendasari pemroduksian dan pemahaman tanda. Dengan demikian, dalam proses semiosis, seseorang dapat menggantikan sesuatu yang diinderanya dengan sebuah tanda sehingga ia mampu memroduksi dan memahami tanda dengan merujuk pada sesuatu tanpa harus terlebih dahulu mengindera sesuatu yang dirujuknya itu.

Danesi dan Perron (1999: 69) memandang kebudayaan sebagai proses penandaan di dalam kognisi seseorang, berupa produksi dan pemahaman tanda berdasarkan konteks yang dikenalnya. Tanda merupakan perantara bagi manusia untuk memahami dunia mereka sehingga proses interpretasi tanda dalam proses semiosis perlu dilanjutkan pada proses interpretasi tanda dalam proses signifikasi kultural untuk mengetahui makna tanda bagi seseorang sebagai interpreter berdasarkan konteks yang mereka ketahui sehingga diperoleh makna tanda yang bersifat terikat dengan budaya (culturebond).

Menurut Danesi dan Perron (1999: 68-69), sebuah tanda diinterpretasi ke dalam tiga tahap, yaitu semiosis, representasi dan signifikasi kultural yang menghubungkan tubuh, pikiran dan kebudayaan sebagai sarana untuk memroduksi dan memaknai tanda.

Semiosis adalah kemampuan berpikir seseorang yang mendasari pemroduksian dan pemahaman tanda. Pada awalnya, seseorang menggunakan inderanya untuk mengenali sesuatu pada tahap 'mengenal (objek) dengan mengindera'. Saat ia menemukan objek yang sama, ia kembali mengenali objek tersebut pada tahap 'mengenal kembali'. Pada akhirnya, ia mampu menggantikan objek yang dikenalinya dengan anggota tubuhnya dalam tahap semiosis, yaitu tahap saat seseorang mampu menggunakan anggota tubuhnya sebagai tanda yang merujuk pada objek yang dikenalinya.

Representasi adalah pemroduksian dan pemahaman tanda yang terjadi ketika seseorang mampu menggantikan objek yang dikenalinya dengan tanda sehingga ia pun mampu menghadirkan kembali objek tersebut melalui tanda. Dengan demikian, ia telah mengembangkan kemampuan berpikirnya dengan memandang tanda sebagai represetasi dari objek yang dirujuk oleh tanda tersebut. Dalam tahap ini, seseorang telah mampu menghubungkan kemampuan sensoris pada tahap semiosis dengan pemikirannya tersebut untuk memroduksi tanda.

Signifikasi Kultural adalah tahap pemroduksian dan interpretasi tanda untuk memahami segala sesuatu berdasarkan konteks tertentu, saat seseorang memahami tanda berdasarkan pengetahuan yang dimilikinya. Signifikasi kultural adalah sarana memahami tanda dengan 
menghubungkan kemampuan sensoris pada tahap semiosis dan kemampuan berpikir pada tahap representasi dengan konteks tertentu dalam dunia yang dikenalnya.

Tanda adalah mediator yang menghubungkan proses interpretasi tanda untuk menghasilkan pemahaman atas fenomena yang dijumpai seseorang di dalam kehidupannya. Dalam semiosis, tanda dihasilkan oleh pengalaman sensoris, dalam representasi tanda dihasilkan oleh kemampuan berpikir, dan dalam signifikasi kultural tanda adalah hasil karya manusia (kebudayaan) yang dihasilkan berdasarkan kesepakatan bersama (dari budaya yang sama) sehingga makna tanda bersifat komunal.

Pada umumnya, interpretasi tanda bersifat culture-bond dan tidak universal, sehingga dua orang yang berasal dari budaya yang berbeda dapat memiliki interpretasi yang berbeda pula atas tanda yang sama. Perubahan jaman yang mengubah budaya masyarakat yang menghasilkan tanda pun akan mengubah makna tanda yang dihasilkan untuk menyesuaikan jaman tersebut (Danesi dan Perron, 1999: 70)

Dalam penelitian ini, tanda adalah setiap unsur dalam strip komik yang dianggap sebagai tanda -yang menjadi objek pemaknaan- bagi pembacanya. Hasil pemaknaan strip komik oleh pembaca kemudian dianalisis untuk menunjukkan keberlangsungan budaya di dalam strip komik. Analisis hasil pemaknaan strip komik tersebut dilakukan untuk menelusuri jejak budaya melalui pandangan pembaca tentang peristiwa budaya yang terdapat di dalam strip komik.

4. Model Analisis Makrosemiotik dan Mikrosemiotik (Danesi \& Perron), Analisis Wacana Kritis (Fairclough), Konsep Konotasi, Mitos dan Ideologi (Barthes)
Analisis hasil pemaknaan strip komik oleh pembaca dibagi menjadi makrosemiotik dan mikrosemiotik. Analisis pertama terdiri atas tiga tahap: (1). Observasi, yaitu mengobservasi latar belakang sosial seluruh individu yang menginterpretasi tanda dan mengumpulkan tanda yang akan diinterpretasi oleh seluruh individu tersebut, (2). Analisis, yaitu menganalisis hasil interpretasi data yang diinterpretasi berdasarkan prinsip dimensionalitas dan menyarikan hasil interpretasi data oleh seluruh individu, dan (3). Sintesis, yaitu menyajikan makna (umum) tanda bagi seluruh individu. Sementara itu, analisis kedua terdiri atas tiga tahap yang serupa: (1). Observasi, yaitu mengobservasi latar belakang sosial setiap individu yang menginterpretasi tanda dan mengumpulkan tanda yang akan diinterpretasi individu tersebut, (2). Analisis, yaitu menganalisis hasil interpretasi data yang diinterpretasi dan menyarikan hasil interpretasi data oleh setiap individu, dan (3). Sintesis, yaitu menyajikan makna (khusus) tanda bagi setiap individu (bagan terlampir).

Sebagai dasar untuk menempatkan teks (strip komik) dalam masyarakat dan kebudayaannya, penulis menggunakan Analisis Wacana Kritis dari Fairclough (1995), dimana pada bagian perubahan sosial dan hegemoni (Fairclough, 1995: 91-111), strip komik dapat dipandang sebagai teks yang dianalisis di dalam tiga tahap, yaitu deskripsi, interpretasi, dan eksplanasi. Namun, berbeda dengan (Fairclough, 1995:89), dalam penelitian ini, strip komik tidak diinterpretasi dalam kotak interpretasi dan interpreter-nya adalah individu dengan latar belakang sosial-budaya yang berbeda dengan strip komik, sehingga terdapat perbedaan hasil interpretasi (bagan terlampir).

Sementara itu, Konsep Konotasi, Mitos, dan Ideologi Barthes (1957: 1972) digunakan sebagai landasan dalam mengambil kesimpulan untuk melihat 
sejauh mana konotasi, mitos dan ideologi tentang kebudayaan yang melekat (embedded) pada strip komik, yang berkembang dalam benak interpreter, berpengaruh pada pandangan mereka tentang peristiwa budaya yang terdapat di dalam strip komik. Sejauh mana naturalness dan historiness menghasilkan konotasi, mitos, dan ideologi yang berada di balik sebuah wacana sehingga disadari atau tidak - maknanya menjadi "goes without saying" (Barthes, 1957: 11) (bagan terlampir).

\section{Metodologi Penelitian}

Penelitian ini menggunakan ancangan kualitatif dan berada dalam wilayah kajian Pragmatik dan Semiotik. Data primer-berupa strip komikdiperoleh dengan menggandakannya dari terbitan aslinya, sedangkan data sekunder-berupa hasil wawancaradiperoleh dengan mewawancarai langsung individu yang menginterpretasi strip komik. Wawancara ini terbagi menjadi dua. Bagian pertama dilakukan untuk mengetahui latar sosial-budaya individu dan bagian kedua dilakukan untuk mengetahui bagaimana individu menginterpretasi teks.

Berdasarkan Analisis Wacana Kritis (Fairclough, 1995), data primer diletakkan sebagai sebuah teks yang berada di dalam masyarakat yang berbeda dengan masyarakat tempat teks tersebut berasal sehingga hasil interpretasinya bisa jadi berbeda berbeda dengan hasil interpretasi teks di tempatnya berasal.

Pada tahap mikrosemiotk, data primer dianalisis dengan meminta individu mengungkapkan implikatur percakapan dari ujaran tokoh strip komik. Berdasarkan hasil analisis data primer, penulis menganalisis data sekunder pertama (hasil pengungkapan implikatur percakapan ujaran tokoh srip komik) untuk mengetahui bagaimana individu mengungkapkannya dan mengapa hasilnya demikian. Pada tahap makrosemiotik, hasil interpretasi strip komik pada tahap mikrosemiotik dianalisis dengan menghubungkannya dengan latar belakang sosial-budaya individu dari data sekunder kedua untuk menjelaskan mengapa hasilnya demikian.

Sebagai simpulan, diperoleh penjelasan tentang konotasi, mitos, dan ideologi yang berkembang di masyarakat tempat individu berada tentang masyarakat tempat strip komik diproduksi beserta kebudayaannya (data primer dan sekunder terlampir).

\section{Analisis}

Dalam penelitian ini, penulis mengambil Strip Komik 'Peanuts' (STP) karya Charles M. Schulz yang pertama kali dimuat di dalam tujuh surat kabar di Amerika Serikat pada 2 Oktober 1950 sebagai objek penelitian. Meskipun nampak seperti strip komik untuk anak dikarenakan seluruh tokohnya adalah anak usia sekolah dasar di Amerika Serikat, STP justru mempertentangkan pandangan anak dan orang dewasa tentang dunia secara luas dan mendalam.

Setiap tokoh dalam STP mengalami antusiasme, frustasi dan konflik yang biasa dialami oleh anak seusia mereka dengan dunia sekolah dan pergaulan siswa sekolah dasar di Amerika Serikat, akan tetapi disajikan dalam gaya penyampaian yang dewasa karena mereka menggunakan bahasa yang rumit dengan kosakata yang cukup canggih, yang pada umumnya berasal dari bidang filosofi, psikologi atau teologi, yang lazimnya digunakan oleh orang dewasa yang terpelajar (Horn, 1996: 237). STP mengangkat masalah yang nampak sederhana dengan cara yang tidak sederhana, sehingga selain menghibur STP juga memperluas wawasan pembacanya (STP terlampir).

Penulis kemudian memilih dua kelompok informan yang berasal dari Indonesia, bukan orang Amerika Serikat tempat STP berasal. Kelompok pertama 
adalah informan yang pernah tinggal dan mengikuti secara langsung peristiwa budaya di Amerika Serikat, sedangkan kelompok kedua adalah informan yang mengikuti secara langsung peristiwa budaya Amerika Serikat di Indonesia karena mereka bekerja pada institusi yang membuat mereka berpartisipasi dalam peristiwa tersebut (biodata terlampir).

Sebagai contoh analisis, penulis mengambil contoh STP seri April Fool $(A F)$ berikut.

\subsection{STP Seri $A F$}
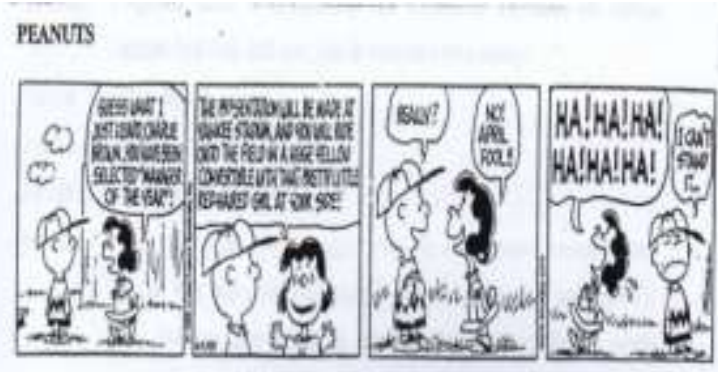

6.2. Enam Ujaran (U1-U6) dalam $\boldsymbol{A F}$

Lucy van Pelt (LVP)

(U1) Guess what I just heard Charlie Brown. You have been selected "Manager of The Year!"

(U2) The presentation will be made at Yankee Stadium, and you will ride onto the field in a huge yellow convertible with that pretty little redhaired girl at your side!

Charlie Brown (CB)

(U3) Really?

Lucy van Pelt

(U4) No! April Fool!!

(U5) Ha! Ha! Ha! Ha!

Charle Brown

(U6) I can't stand it.

\subsection{Pengungkapan Implikatur Percakapan dari U1-U6 dalam $A F$ oleh Informan 1 (I1)}

Implikatur percakapan dari U1-U2 adalah LVP memperdaya (make a fool of) CB saat $A F$. Hal tersebut diperoleh I1 berdasarkan pengetahuannya tentang peristiwa budaya Amerika berupa $A F$ saat seseorang lazimnya memperdaya orang lain. Selain itu, I1 juga mengetahui karakter LVP dan CB serta tema yang sering diangkat dalam STP tentang mereka berdua, yaitu LVP memperdaya CB karena LVP menganggap CB terlalu mudah diperdaya. Meskipun I2 mengetahui bahwa ujaran LVP tidak benar, U1 relevan dengan situasi percakapan tersebut karena disampaikan saat $A F$ dan selaras dengan situasi yang biasa terjadi pada interaksi kedua tokoh tersebut. Hal yang sama disampaikan pula untuk U2.

Implikatur percakapan dari U3 adalah CB terlalu mudah diyakinkan oleh LVP (bahkan saat ia dibohongi). Seperti halnya implikatur percakapan dari U1U2, implikatur percakapan U3 diperoleh I2 dari pengetahuannya tentang karakter LVP dan CB serta tema yang sering diangkat dalam STP tentang mereka berdua. Meskipun I2 mengetahui bahwa ujaran LVP tidak benar sehingga pertanyaan $\mathrm{CB}$ pun tidak akan memperoleh jawaban yang benar pula, U3 relevan dengan situasi percakapan tersebut karena ia mengetahui kepribadian LVP dan CB dalam STP dan situasi yang biasa terjadi dalam $A F$.

Hal yang sama disampaikan pula untuk U4, U5 dan U6 karena I1 berpendapat bahwa ketiganya hanya menunjukkan keberhasilan LVP membuat CB mempercayai apa yang dikatakannya sekalipun itu tidak benar dan sudah seringkali LVP berhasil melakukan hal yang sama.

\subsection{Analisis Hasil Interpretasi $A F$ oleh I1}

I2 memandang $A F$ sebagai salah satu seri dengan tema LVP memperdaya CB (continuity) karena dalam STP LVP selalu berhasil memperdaya $\mathrm{CB}$ dan sebaliknya $\mathrm{CB}$ selalu berhasil diperdaya oleh LVP. Sebagai tambahan I2 menyatakan bahwa seri ini merupakan simbol ketidakberdayaan kaum lemah atas kaum kuat di dalam masyarakat. 
Dengan demikian, LVP merupakan representasi dari kaum kuat sedangkan CB merupakan representasi dari kaum lemah.

\subsection{Pengungkapan Implikatur Percakapan dari U1-U6 dalam $A F$ oleh Informan 2 (I2)}

Implikatur percakapan dari U1-U2 adalah LVP mengerjai CB saat $A F$. Hal tersebut diperoleh I2 berdasarkan pengetahuannya tentang peristiwa budaya Amerika berupa $A F$ saat seseorang bebas mengerjai orang lain. Meskipun I2 mengetahui bahwa ujaran LVP tidak benar, U1 relevan dengan situasi percakapan tersebut karena disampaikan saat $A F$. Hal yang sama disampaikan pula untuk U2.

Implikatur percakapan dari U3 adalah CB sangat mempercayai LVP (meski ia membohonginya). Meskipun I2 mengetahui bahwa ujaran LVP tidak benar sehingga pertanyaan $\mathrm{CB}$ pun tidak akan memperoleh jawaban yang benar pula, U3 relevan dengan situasi percakapan tersebut karena ia mengetahui situasi serupa dalam $A F$ yang sering ia lakukan.

Implikatur percakapan dari U4 adalah LVP tidak tega kepada CB yang percaya padanya dan mengharapkan jawaban 'ya' darinya untuk terus membohonginya sehingga ia segera menjawab dengan U5 yang mengandung implikatur berkebalikan dari U4 karena, bagi I2, tawa LVP justru menunjukkan bahwa ia sangat tega kepada CB karena ia tertawa puas setelah berhasil mengerjai CB. U4 relevan dengan situasi percakapan tersebut karena mengandung kebenaran, sedangkan U5 relevan dengan situasi percakapan tersebut karena menunjukkan ekspresi kepuasan (keberhasilan LVP mengerjai CB).

Implikatur percakapan dari U6 adalah CB membenci LVP atas perbuatannya karena kata ' $i t$ ' merujuk pada apa yang dilakukan LVP. U6 relevan dengan situasi percakapan tersebut karena menunjukkan ketidaksanggupan $\mathrm{CB}$ dalam menerima perlakuan LVP.

\subsection{Analisis Hasil Interpretasi $A F$ oleh I2}

Berbeda dengan I1, I2 justru menghubungkan karakter LVP dengan Amerika Serikat (AS) yang berhasil memperdaya negara lain dan menghubungkan karakter $\mathrm{CB}$ dengan negara lain yang berhasil diperdaya oleh AS. Dengan demikian, LVP adalah representasi dari $\mathrm{AS}$ dan $\mathrm{CB}$ adalah representasi dari negara lain.

Menurut I1, jika dihubungkan dengan situasi yang ada, seri $A F$ menunjukkan bahwa AS memandang rendah (under estimate) negara lain yang ia pandang rendah (inferior) karena mudah percaya sehingga mudah pula diperdaya. I1 menambahkan bahwa pada umumnya negara yang dipandang rendah tidak menyadari bahwa mereka diperdaya karena tidak berdaya menghadapi tipu daya negara yang kekuasaannya jauh melampaui kekuasaan mereka. Bahkan ketika hal tersebut direpresentasikan dalam STP yang dikonsumsi oleh negara yang dipandang rendah tersebut.

\section{Simpulan}

Berdasarkan analisis perubahan sosial dan hegemoni dalam Analisis Wacana Kritis Fairclough (1995: 91111), teks berupa STP seri $A F$ dianalisis dalam tiga tahap, yaitu deskripsi, interpretasi dan eksplanasi oleh individu (dari Indonesia) yang tidak berasal dari negara tempat STP berasal (Amerika Serikat) sehingga teks dianalisis menggunakan sudut pandang yang berbeda dengan sudut pandang penulis STP. Hasil analisis tersebut adalah: (1) deskripsi STP seri $A F$ berupa adanya peristiwa budaya Amerika berupa $A F$ dimana ada pihak yang memperdaya (LVP) dan pihak yang diperdaya (CB), 
(2) interpretasi peristiwa budaya Amerika dalam STP seri $A F$ berupa adanya fenomena 'yang kuat' dan 'yang lemah' dalam masyarakat Amerika Serikat yang direpresentasikan oleh LVP (kuat) dan CB (lemah), dan (3) penjelasan berupa adanya budaya penindasan dari 'yang kuat' kepada 'yang lemah' dalam masyarakat Amerika Serikat yang direpresentasikan oleh LVP (kuat) dan CB (lemah).

Dengan menggabungkan hasil pengungkapan implikatur percakapan enam ujaran (U1-U6) dalam STP seri $A F$ dan analisis hasil pemaknaan pembaca atas implikatur percakapan tersebut menggunakan teori pragmatik berupa Teori Relevansi Sperber dan Wilson (1986: 1996); diperoleh temuan berupa adanya karakteristik LVP dan CB serta tema yang sering diangkat oleh penulis STP tentang mereka berdua. Karakteristik LVP adalah tokoh yang merasa paling cerdas dan senang memperdaya tokoh lain yang dianggap tidak secerdas dirinya, sedangkan karakteristik CB adalah tokoh yang merasa dirinya seorang pecundang (looser) karena sering gagal melakukan sesuatu sehingga mudah diperdaya oleh tokoh lain. Tema yang sering diangkat penulis STP tentang LVP dan CB adalah LVP yang memperdaya $\mathrm{CB}$, khususnya dalam permainan softball dimana $\mathrm{CB}$ selalu gagal memukul bola sehingga tak seorangpun mau bermain dengannya. Dalam STP seri $A F$, ujaran LVP saat memperdaya $\mathrm{CB}$ dianggap dapat dipahami pembaca meskipun mengandung ketidakbenaran karena lazimnya seseorang memperdaya orang lain pada peristiwa budaya Amerika berupa $A F$, misalnya dengan berbohong. U1-U6 mengandung tindak komunikasi yang ostensif dengan relevansi optimal yang memiliki efek kontekstual sehingga pembaca memiliki usaha pemrosesan ujaran yang kecil untuk memahami U1U6. Dengan demikian, dapat dikatakan bahwa derajad relevansi U1-U6 tinggi. $\begin{array}{llr}\begin{array}{c}\text { Dengan } \\ \text { analisis }\end{array} & \begin{array}{r}\text { menggabungkan } \\ \text { makrosemiotik }\end{array}\end{array}$ mikrosemiotik mengunakan teori semotik berupa Teori Signifikasi Kultural Danesi dan Perron (1999) diperoleh temuan berupa: (1) individu yang menginterpretasi STP seri $A F$ adalah mereka yang mengetahui dan ikut merayakan peristiwa budaya Amerika berupa $A F$, baik di Amerika Serikat maupun di Indonesia sehingga ia mampu memaknai tanda dalam STP seri $A F$ yang mengandung peristiwa budaya Amerika berupa $A F$; (2) hasil interpretasi STP seri $A F$ adalah adanya tokoh 'kuat' yang memperdaya tokoh 'lemah' yang direpresentasikan oleh LVP (yang kuat) dan CB (yang lemah); (3) makna STP seri $A F$ adalah adanya simbol pertentangan antara 'kaum kuat' dan 'kaum lemah' dalam budaya Amerika dan budaya pada umumnya yang direpresentasikan oleh LVP (yang kuat) dan CB (yang lemah).

Ketika hasil interpretasi I2 dihubungkan dengan Konsep Konotasi, Mitos dan Ideologi dari Barthes (1957;1972), maka dalam STP seri $A F$ terdapat pertentangan antara 'si kuat', yaitu LVP sebagai representasi AS yang memiliki konotasi negatif sebagai pihak yang memperdaya pihak lain yang lebih lemah dan 'si lemah' yaitu CB sebagai representasi negara lain yang memiliki konotasi negatif sebagai pihak lemah yang tidak berdaya menghadapi pihak yang lebih kuat. Dengan demikian, dapat dikatakan bahwa mitos yang berkembang dalam benak I2 adalah AS merupakan 'negara kuat' yang mampu memperdaya negara lain yang 'lemah'. Jika mitos tersebut menguat, maka secara tanpa sadar penilaian I 2 terhadap seri $A F$ akan dipengaruhi oleh ideologi tentang AS yang memperdaya negara lain. Tidak lagi murni tentang 'si kuat' yang direpresentasikan oleh LVP dan 'si lemah' yang direpresentasikan oleh CB seperti yang diperoleh I1. 
Sebagai catatan dapat disampaikan bahwa hasil interpretasi pembaca berkaitan erat dengan latar budaya masing-masing. Latar budaya I1 yang merayakan peristiwa budaya Amerika di AS tidak membuatnya memandang AS sebagai simbol 'si kuat' yang menindas negara lain sebagai 'si lemah'. Sementara itu, latar budaya I2 yang hanya ikut memeriahkan peristiwa budaya Amerika di Indonesia membuatnya memandang AS demikian berdasarkan pengaruh budaya di sekitarnya meskipun ia juga ikut memeriahkan peristiwa budaya negara yang dianggapnya penindas itu.

\section{Daftar Pustaka}

Barthes, R. 1972. Mythologies (terj. Annette Lavers). London: Vintage.

Danesi, M dan Perron, P. 1999. Analysing Cultures. An Introduction and Handbook. Indianapolis: Indiana University Press.

Fariclough, N. 1995. Critical Discourse Analysis: The Critical Study of Language. London: Longman.

Grice, H.P. 1975. "Logic and Conversation" dalam Cole, P. Dan Morgan, J. (ed.). Syntax and Semantics: Speech Acts. New York: Academic Press.

Horn, M. 1996. 100 Years of American Newspaper Comics. New York: Gamercy Books.

Kunzle, D. (1963. The Early Comic Strips. Berkeley: University of California Press.

Nöth, W. 1995. Handbook of Semiotics. Indianapolis: Indiana University Press.

Sabin, R. 1996. Comics, Comix \& Graphic Novels.A History of Comic Art. London: Phaidon Press.

Sperber, D dan D Wilson, (1986). A Relevance.Communication and Cognition. Cambridge: Cambridge University Press.
Tabrani, P. 2005. Bahasa Rupa. Bandung: Kelir.

Thomas, J. 1995. Meaning in Interaction. London: Longman.

Wijana, I.D.P. 2004. Kartun: Studi tentang Permainan Bahasa. Yogyakarta: Ombak. 